\title{
Research in International Business

\section{The housing market and the credit default swap premium in the UK banking sector: A VAR approach ${ }^{\text {is }}$}

\author{
Nadia Benbouzid ${ }^{\mathrm{a}}$, Sushanta Mallick ${ }^{\mathrm{b}, *}$, Keith Pilbeam ${ }^{\mathrm{c}}$ \\ a University of Greenwich, Business School, Accounting and Finance Department, Old Royal Naval College, 10 Park Row, London, SE10 \\ 9LS, UK \\ b Queen Mary University of London, School of Business and Management, Mile End Road, London E1 4NS, UK \\ c City, University London, Department of Economics, Northampton Square, London EC1V OHB, UK
}

\section{A R T I C L E I N F O}

\section{Article history:}

Received 28 August 2016

Received in revised form 3 December 2016

Accepted 30 January 2017

Available online $\mathrm{xxx}$

\section{JEL Classifications:}

G1

G2

Keywords:

CDS premium

House prices

UK banking sector

Credit risk

Financial crisis

\begin{abstract}
A B S T R A C T
In the wake of the recent global financial crisis, this paper investigates the determinants of the Credit Default Swap premium in the UK banking sector for the period January 2004-April 2011. Employing a VAR model, we focus on the roles played by house prices, the yield spread, the UK TED spread and the FTSE 100 index. Our main results suggest that the CDS premium significantly increases in the medium term following a positive shock to the house price index, reflecting that continued house price appreciation can hide the likelihood of default risk, as shown in the insignificant response in the short run. We also find that a positive shock to the CDS premium significantly reduces house prices because it induces banks and other financial institutions to lend less, reducing the demand for housing and exerting further downward pressure on house prices. While a positive shock to stock prices lowers the CDS premium, a positive shock to the liquidity premium increases the CDS premium. Finally, our variance decomposition analysis shows that the house price shock explains over $19 \%$ of the long-run forecast-error variance of the CDS premium, while shocks in other variables each explain less than $8 \%$ of this forecast-error variance.
\end{abstract}

(c) 2017 Elsevier B.V. All rights reserved.

\section{Introduction}

A great deal has been written about the financial crisis that started in the summer of 2007. The crisis started with a housing bubble in the United States but because of contagion, it spread from the housing market to affect the global financial system. The growth of the credit default swap market coincided with the rapid growth of securitization activities in mortgage backed securities (MBS) and collateralized debt obligations (CDOs). During the period 2002-7, the US economy witnessed an economic boom driven by low interest rates and a housing construction and price boom. Financial innovation enabled banking and other financial institutions to expand their lending capacities and other mortgage contracts to low-income consumers, many of whom were ultimately unable to honour their debt obligations. Banks transferred junk loans, subprime and other mortgages into Special Purpose Vehicles (SPVs) and then on-sold these assets as Residential Mortgage Backed Securities and CDOs.

\footnotetext{
We gratefully acknowledge the constructive comments made by an anonymous reviewer of this journal on an earlier version of this paper and also for suggestions made by the editor. The usual caveat applies.

* Corresponding author at: School of Business and Management, Queen Mary University of London, Mile End Road, London E1 4NS, UK

E-mail addresses: n.benbouzid@greenwich.ac.uk (N. Benbouzid), s.k.mallick@qmul.ac.uk (S. Mallick), k.s.pilbeam@city.ac.uk (K. Pilbeam).
} 
At the same time, there was a large growth in Credit Default Swap (CDS) contracts which were used by banks and financial institutions as a form of insurance against the occurrence of a credit event. Banks and hedge funds use such contracts for both hedging and speculative purposes. The holder of a CDS contract has no obligation to own the underlying instrument. This characteristic makes it different from insurance contracts in which the holder of the contract is required to have an "insurable interest". In addition to mitigating the concentration of credit risk at banks and financial institutions, CDS contracts allow institutions providing credit to diversify their credit risk exposure and increase their lending capacity. Furthermore, CDS contracts helped financial institutions issuing debt to decrease their cost of capital by reducing the level of risk for investors holding bond instruments.

The CDS premium represents a reliable proxy for credit risk. It can be interpreted as the price of insuring against a credit event in the underlying asset. The buyer of the CDS contract makes a series of quarterly premium payments to the protection seller. If there is a credit event such as a default, restructuring or bankruptcy, the protection seller is bound by law to pay the holder of the CDS contract the par value of the underlying security upon receipt of the security from the protection buyer. If no credit event occurs, the protection seller simply receives the quarterly premium payments from the protection buyer.

The recent literature on CDS premiums and credit risk determinants can be split into two main streams. The first has mainly focused on macroeconomic drivers, including interest rates, yield spreads and inflation, see for example, Lekkos and Milas (2001), In et al. (2003), and Alexander and Kaeck, (2008) using a single-equation setting. The second has looked at bank-level characteristics, such as asset quality, credit ratings, leverage, liquidity and volatility, see for example, CollinDufresne et al. (2001), Campbell and Taksler, (2003), Hull et al. (2004), Fabozzi et al. (2007) and Chiaramonte and Casu (2013) that use single-equation panel frameworks.

In this paper, we build upon the contribution of Benbouzid and Mallick (2013) who established the role of house prices in a single cointegrating equation. We contribute to the growing literature on CDS premiums, by combining the key financial factors in a unified multivariate time series framework with reference to the UK banking sector CDS and UK housing market. By using a dynamic multivariate framework in a VAR setting, we are able to undertake a shock-analysis to more fully explore the relationship between CDS banking sector premium and the UK housing market while considering the key money market, bond market and stock market variables.

An important part of our research is to show the impact of house prices on the CDS market which has been largely overlooked in the previous literature. There are several reasons to believe that house prices have a direct impact on credit risk. Firstly, the recent financial crisis was in large part due to the ending of the housing boom. The boom meant both higher house prices and a related increase in construction activity. The ending of the house price boom and subsequent slide in construction activity and increase in defaulting mortgages played a role in driving up CDS premiums. In the UK banking sector, the CDS premium increased from an average of only 9 basis points in early July 2007 to over 220 basis points in March 2008. Given the close linkage between the housing market and the credit market, there is a priori strong evidence to suggest that changes in house prices affected CDS premiums.

We use a VAR framework to analyse the impact of the housing market in driving the CDS premium on the UK banking sector. We analyse the short-run effects of house prices on CDS premiums before, during and after the financial crisis. Our empirical findings from the recursive VAR model indicate that the house price appreciation did limit the CDS premium on the banking sector in the pre-crisis period. Our results show that a positive shock to CDS premium impacts negatively on house prices. Following a shock in house prices, the CDS premium remains insignificant on immediate impact, but in the medium term there is a rise in credit risk perception, and hence defaults rise, increasing the CDS premium on the banking sector. Other variables are found to be far less important in the VAR model as shown in the variance decomposition analysis.

The paper is structured as follows: Section 2 discusses the determinants of credit risk and the CDS premium. Section 3 describes the data and proxies used for examining the determinants of CDS premiums in the UK banking sector. Section 4 presents the VAR method employed to analyse the impact of house prices on the CDS premium on the UK banking sector and discusses the results obtained. Section 5 concludes.

\section{Literature review}

In the wake of the recent financial crisis, the CDS market has attracted a lot of attention from governments, regulators and central banks due to its large market size and the subsequent impact it had on financial institutions such as the American International Group (AIG), Lehman Brothers and Bear Sterns, among others. Despite the very large and rapidly growing size of the CDS market, in the run up to the financial crisis, there was only limited coverage in the academic literature. However, since the crisis there has been an upsurge of interest in understanding the determinants of the CDS premium and in the role that the CDS market may have on financial stability.

The early modelling of credit risk relied upon a reduced form approach as introduced by Litterman and Iben (1991) and Jarrow and Turnbull (1995). The reduced form modelling of credit risk does not directly and explicitly link default and firmlevel economic variables. Instead, it revolves around a stochastic process that considers an exogenous hazard rate, which when multiplied over a specific time period, leads to a risk neutral default probability. As such, the reduced form default model does not condition default on a specific threshold value of a firm's dynamics which implies that there is no parameter connected to the value of the firm that needs to be estimated. In the reduced form model, default occurs in a sudden and unpredictable way; Jarrow and Turnbull (1995) refer to this as a 'jump default' model, with the underlying assumption 
that default occurs in an exogenous manner. According to Duffie and Singleton (1997), the jump intensity parameter will ultimately depend upon macroeconomic factors.

The early literature on the determinants of CDS premiums was to some extent hindered by the limited amount of data available and the lack of transparency of the credit derivatives market. CDS contracts are mainly traded in the over-thecounter (OTC) market and not all trades are recorded. Authors such as Blanco et al. (2005) and Zhu (2006) investigate the relationship between credit spreads, that is, the difference between corporate bonds yields and Treasury bond yields and CDS premiums. Both studies find that there is a strong theoretical and empirical link between rising corporate bonds spreads and rising CDS premiums. However, both studies also show that there can be significant empirical deviations from the theoretical relationship.

An additional CDS premium determinant that has been widely recognized in the past literature is liquidity, see for example Bongaerts et al. (2011) who find that liquidity is a small but significant determinant of CDS premiums. Mamatzakis (2013) takes account of liquidity by using the difference between the bid-ask spread for sovereign debt, and finds that deteriorating liquidity conditions feed into higher sovereign bond spreads and CDS premiums. Similarly, Annaert et al. (2013) look at bank specific liquidity as measured by the bid-ask quote and they also capture market wide liquidity in an indirect way by using the swap and corporate bond spreads. They show that CDS liquidity and other market and business variables play an important role in explaining credit spread changes. Fontana and Scheicher (2010) investigate the Eurozone Sovereign CDS markets relative to the underlying pricing of government bonds and show that the difference between CDS premiums and bond spreads is mostly due to common factors. They find that after the Eurozone crisis in September 2008, the CDS premiums have on average exceeded bond spreads which may have been driven by 'flight to liquidity' effects and limits to arbitrage.

According to the structural default models, an important factor that influences CDS premiums is the risk free interest rate. Researchers such as Anderson and Sundaresan (2000), Duffie and Singleton (1997), Duffee (1998), Lekkos and Milas (2001) and In et al. (2003) find that an increase in the risk free interest rate leads to a reduction in the default probability. The rationale behind this finding is that the risk free interest rate affects the risk neutral drift in the firm value process. As the risk free interest rate goes up, the risk neutral drift also increases, causing the probability of default of a firm to go down, see Longstaff and Schwartz (1995) and Collin-Dufresne et al. (2001). Skinner and Townend (2002), show that both microeconomic and macroeconomic indicators should be employed when investigating the determinants of credit spreads. They argue that CDS contracts are similar to put options and that in addition to the credit rating of the underlying entity, other important variables that should be considered, include the risk-free interest rate, stock returns of the reference entity, the volatility of interest rates, time to maturity and the put exercise premium.

Houweling and Vorst (2002) compare the CDS premium implied by a simple reduced-form framework with the market CDS premium derived from the underlying bond's credit spread. They show that the spread on a par fixed-coupon risky bond over the par fixed-coupon risk-free bond should be equal to the CDS premium. This equation is satisfied only when the payment dates on the CDS match those of the bond, with the recovery on default remaining a constant fraction of the face value. They find that a simple reduced form model with a constant recovery rate outperforms the market practice of directly comparing bond credit spreads to CDS premiums. Importantly, their model works well for investment grade CDS contracts only if swap or repo rates are used as a proxy for the risk free interest rate.

Besides the issue of the best proxy for the risk free interest rate, an additional factor that must be considered as a determinant of the CDS premium is the slope of the yield curve. A steeper yield curve would indicate that there is an expectation of an increase in future interest rates, suggesting a robust economy and a reduced CDS premium. If, however, the yield curve is negatively sloped or becomes less positively sloped then this indicates a greater risk of recession which will lead to an increase in corporate defaults and higher CDS premiums. A similar argument for the relationship between the slope of the yield curve and the future state of economic activity is made in Estrella and Hardouvelis (1991). Authors including, Fehle (2003), and Kobor et al. (2005) present empirical evidence supporting the presence of a negative relationship between the CDS premium and slope of the yield curve. Apergis and Mamatzakis (2014) show that the factors including, the level of interest rates, the slope of the yield curve, whether CDS contracts are physically settled and the extent of how closely assets trade to par, tend to affect CDS premiums and make the CDS premium higher than the actual credit spread.

Galil et al. (2014) investigate the determinants of the CDS premium by considering the adjusted change in the CDS premium, which they calculate as the difference between the CDS premium and the premium fluctuation in the CDS index. After examining the CDS premiums changes for 718 US firms over the period 2002-2013, they find that contrary to previous studies, market variables have significant explanatory power after controlling for firm-specific variables from structural models. In particular, they find that stock returns, the change in stock return volatility and the change in the median CDS premium in the rating class are important determinants of CDS premiums.

Besides discussing the importance of the theoretical factors affecting credit spreads, the literature also highlights the significance of considering overall market conditions and market volatility in determining credit risk. Friedman and Kuttner (1998) find that the US business cycle impacts on the number of defaults and credit risk as measured by the difference between the yield on commercial paper and Treasury bills. Altman et al. (2005) show that default probabilities as well as recovery rates change depending on the course of the business cycle. In general, better economic conditions and a more favourable business climate will ultimately lead to a reduction in the probability of default and a rise in the expected recovery rate. This in turn translates into reduced CDS premiums. In addition, Pesaran et al. (2006) show that credit spreads are affected by both the domestic and international business cycles. Bedendo and Colla (2015) conduct a time fixed effect 
analysis, by incorporating macroeconomic fundamental indicators such as the Eurozone stock market index returns, stock market volatility and the term structure of the yield curve and find that these are significant determinants of the CDS premium.

An additional factor that has been recognized in the literature as an important credit spread determinant is market volatility. The relationship between stock price volatility and CDS premiums is expected to be positive, as more volatile stocks typically signal a higher risk of default. Collin-Dufresne et al. (2001) use the VIX index based upon implied volatility of the S\&P 500 index options, as a proxy for market volatility. Equity volatility and equity returns have also been used by Byström (2005), Alexander and Kaeck (2008), Das et al. (2009) and Ericsson et al. (2009). The results obtained by Byström (2005) indicate that CDS premiums narrow in response to rising stock prices and that higher stock price volatility leads to an increase in CDS premiums. Alexander and Kaeck (2008) demonstrate that during periods of economic instability CDS premiums have a tendency to strongly react to equity volatility whereas during a stable economic climate, CDS premiums are generally more sensitive to equity returns. Das et al. (2009) using a sample of 2860 quarterly CDS premiums find that a model of distress using both accounting metrics and market-based structural models of default performs better than using just one of the models and as such are complementary in pricing CDS premiums. While Ericsson et al. (2009) using both univariate and multivariate regressions find that a combination of volatility and leverage has substantial explanatory power in determining CDS premiums. In a similar vein, Alexander and Kaeck (2008), Boss and Scheicher (2005), GonzálezHermosillo (2008), Pan and Singleton (2008) and Tang and Yan (2010) have used the 30-day implied volatility of the EURO STOXX 50 shares to measure economic uncertainty in Europe.

Annaert et al. (2013) use different proxies for historical volatility to model bank CDS premiums in the Eurozone area. One of the proxies they employ for market volatility is to compute weekly historical standard deviations on stock returns; they also use volatilities based on large windows of daily data and absolute weekly returns, squared weekly returns, ranges and mean absolute deviations to test the robustness of their results. Cao et al. (2010) use market conditions when analysing CDS premiums, and they argue that CDS contracts are similar to out-of-the-money put options since both offer a low cost and effective protection against downside risk. They find that the implied volatility from put options is an important determinant of CDS premiums and that individual firms' put option-implied volatility dominates historical volatility in explaining the time-series variation in CDS premiums. Their result can be explained by the fact that implied volatility is a more efficient forecast for future realized volatility than historical volatility.

The impact of financial leverage as a determinant of CDS premiums was originally put forward by Eom et al. (2004). In their study, Annaert et al. (2013) also examine the role of financial leverage relative to the market value as a market indicator affecting CDS premium. Both Annaert et al. (2013) and Collin-Dufresne et al. (2001) use bank stock returns to proxy for the changes in the degree of financial leverage. The findings from Annaert et al. indicate that as stock returns decrease, the level of leverage as a multiple of market value rises. They argue that despite the fact that weekly stock returns are used as a proxy for leverage, it is also likely that weekly stock returns would impact on the firm's future performance and viability. Thus, if stock returns are positive, this can be taken as an indication of good performance and result in lower CDS premiums and vice-versa. In Düllmann and Sosinska (2007), CDS premiums are used as market indicators of bank risk, based on abnormal stock returns, market index returns, the swap spread and the bid-ask spread. While Ericsson et al. (2009) demonstrate that theoretically implied variables, such as leverage and volatility explain a significant proportion of CDS fluctuations, Galil et al. (2014) find that leverage, defined as the book value of debt divided by the sum of book value of debt and the market value of equity is a significant factor or fluctuations in the CDS premium.

A stream of literature emerged in the early 2000s on credit spreads, investigating the existing link between CDS premiums and credit ratings. The expected link is fairly straightforward in that higher credit ratings are indicative of a better asset quality of the underlying instrument, while a lower credit rating would reflect lower quality and riskier assets, see for example, Norden and Weber (2004) and Galil and Soffer, (2011). The link is confirmed empirically in Hull et al. (2004), Cossin et al. (2002), Fabozzi et al. (2007) and Karagozoglu and Jacobs (2010) who all show that credit ratings are significant determinants of CDS premiums. In addition, Alper et al. (2012) show the significance of credit ratings when analysing the sovereign CDS premiums.

Other authors identify the importance of considering bank-level variables as drivers of CDS premiums. Chiaramonte and Casu (2013) proxy asset quality using two financial ratios, namely; the ratio of loan-loss reserves to gross loans and unreserved impaired loans to equity and find that both are significant drivers of the CDS premium before, during and after the recent financial crisis. Ötker-Robe and Podpiera (2010) look at the fundamental determinants of credit default risk for large and complex EU financial institutions. The authors use three distinct ratios to reflect the quality of assets, namely: loan-loss provisions to total loans, the share of non-performing loans to total loans and the loan-loss to reserves ratio and find that they can help explain CDS premiums. In a similar vein, Kick and Koetter (2007) also used the ratio of non-performing loans to total assets as an indicator of asset quality to determine the drivers of bank risk in the German banking sector. In sum, there is a large consensus in the literature that a lower asset quality implies that banks become more-risky driving up banking sector CDS premiums.

Besides asset quality, the literature also identifies the importance of using other bank specific variables when investigating the determinants of bank credit spreads and CDS premiums, namely; liquidity, leverage, regulatory capital and the level of operations. As mentioned previously, while one strand of the literature has examined the significance of leverage as a factor determining CDS premiums, other studies such as, Collin-Dufresne et al. (2001), and Alexander and Kaeck (2008) have used bank stock returns as a proxy for leverage, among other determinants namely credit ratings and market capitalization. Apergis 
Table 1

Explanatory variables and expected signs on the coefficients.

\begin{tabular}{lll}
\hline Variables & Type of the Variable & Description of the variables \\
\hline $\ln ($ CDS $)$ & Dependent & Natural logarithm of the UK banking sector CDS premium \\
$\ln ($ HP $)$ & Explanatory & Natural logarithm of the House Price Index \\
Yield Spread & Explanatory & 30 UK Year Treasury Bond -3 month UK Treasury Bill \\
TED & Explanatory & 3 month fLIBOR -3 month UK Treasury Bill \\
$\ln ($ FTSE100) & Explanatory & Natural logarithm of the FTSE100 Stock Index. \\
\hline
\end{tabular}

Table 2

Summary descriptive statistics of the CDS premium and its determinants.

\begin{tabular}{|c|c|c|c|c|c|}
\hline & $\ln (\mathrm{CDS})$ & In(House Price Index) & Yield Spread & $\ln ($ FTSE100) & TED \\
\hline Mean & 3.511 & 5.785 & 1.000 & 8.577 & 39.6 \\
\hline Median & 3.127 & 5.787 & 0.082 & 8.589 & 18.5 \\
\hline Std. Dev. & 1.371 & 0.067 & 2.042 & 0.142 & 41.4 \\
\hline Minimum value & 1.584 & 5.613 & -1.812 & 8.214 & 10.0 \\
\hline Maximum value & 5.396 & 5.917 & 4.108 & 8.814 & 194.7 \\
\hline
\end{tabular}

and Mamatzakis (2014) examine the dynamics of selected euro-area sovereign bonds by employing a factor augmenting vector autoregressive (FAVAR) model. They identify the underlying transmission mechanisms of several factors, such as, market liquidity and credit risk as determinants of CDS premiums for the euro-area sovereign debts of Greece and Ireland.

Having reviewed the literature on the factors affecting credit spreads, and more specifically CDS premiums, in the next section, we describe the data we have used in our analysis. Since we are undertaking an aggregate analysis for the UK banking sector, we focus on the key variables that matter at the aggregate level in the money and capital markets and in particular the housing market, which has not yet been explored as a channel in driving bank CDS premiums.

\section{Data description}

The dataset used in this paper looks at behaviour of the UK banking sector CDS premium prior, during and after the financial crisis, over the period of January 2004-April 2011. We use the monthly 5-Year Credit Default Swap (CDS) index as a proxy for credit risk in the UK banking sector. The CDS data on the UK banking sector was obtained from Credit Market Analysis (CMA) Group who started publishing this index in 2004. Our estimations use the mid-rate CDS premium, which is expressed in basis points.

We examine the CDS premium for the UK banking sector against four financial explanatory variables. The first explanatory variable is the natural logarithm of the UK house price index published by Nationwide. A rise in house prices is predicted to lower or not increase the bank CDS premium as it makes defaults by mortgage borrowers less likely. The second explanatory variable we use is the yield spread defined as the yield difference between the UK 30-Year Treasury bond and the 3-Month UK Treasury bill. As suggested in the previous literature, the slope of the yield curve is an important determinant of the CDS premium. The third explanatory variable that reflects short term liquidity conditions is the UK TED spread, defined as the difference between the 3-month ELIBOR and the 3-month UK Treasury Bill. The UK TED spread represents a reliable indicator of interbank credit risk at the short term horizon, see for example, Aizenman et al. (2013). Finally, as a fourth explanatory variable we use the UK FTSE 100 index to measure the impact of capital markets on the CDS premium. There should be a negative relationship between the performance of the stock index and the CDS premium, see Das et al. (2009). As the performance of the FTSE100 improves, market conditions also improve implying that there is a lower probability of default and hence reduced credit risk. The data for the four explanatory variables was obtained from Thompson Reuters Datastream, at monthly frequency, ranging from January 2004 to April 2011. Table 1 outlines the expected signs of the dependent and independent variables and their predicted relationships. In Table 2 we summarize the descriptive statistics.

The fluctuations of the dependent and all the explanatory variables are depicted in Fig. 1 of this paper. As can be seen the variables are non-stationary and this is also confirmed in our empirical tests.

\subsection{Results on unit root tests with breaks}

In this sub-section, we discuss the stationarity properties of the variables before undertaking the VAR analysis. There are various tests that exist without and with breaks to identify whether a series is stationary or not, including the benchmark Augmented Dickey-Fuller (ADF) test. However, it should be noted that the sample period (2004-2011) we are considering includes a highly sensitive period, as it covers both the period before the crisis and after the crisis period. Therefore, it is essential to conduct robust stationarity tests that will account for the occurrence of the structural breaks as a result of the crisis.

In addition to the traditional unit root tests, several other tests were proposed for determining the break point in an endogenous manner from the data. As such, Lumsdaine and Papell (1997) extended the Zivot and Andrews (1992) singlebreak test to allow for the occurrence of two structural breaks. However, it should also be noted that these endogenous 

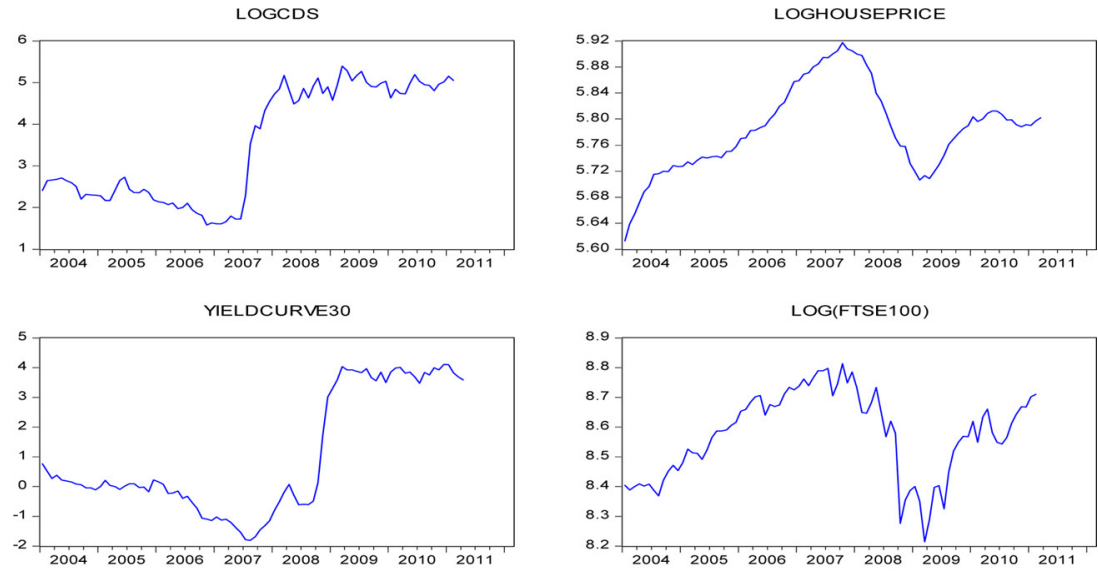

TED

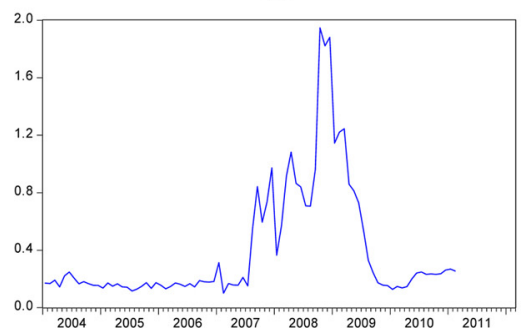

Fig. 1. Graphical illustration of the non-stationarity of the CDS premium, House Price Index, Yield Spread and the FTSE 100 index series.

Table 3

Testing for Unit Roots (variables in levels)

\begin{tabular}{|c|c|c|c|c|c|c|c|}
\hline & $\mathrm{ADF}$ & DFGLS & $\begin{array}{l}\text { Phillips } \\
\text { Perron Test }\end{array}$ & $\begin{array}{l}\text { Kwiatowski Phillips } \\
\text { Shmidt Shin (KPSS) }\end{array}$ & Zivot-Andrews & $\begin{array}{l}\text { Lumsdaine- } \\
\text { Papell }\end{array}$ & Lee-Strazicich \\
\hline $\ln (\mathrm{CDS})$ & -0.5865 & -0.3986 & -0.7419 & $0.9086^{* *}$ & $\begin{array}{l}-7.5062^{* *} \\
\text { [August 2008] }\end{array}$ & $\begin{array}{l}-6.2853 \\
{[2007: 04} \\
2008: 04]\end{array}$ & $\begin{array}{l}-5.6303^{* *} \\
{[2007: 02} \\
2007: 12]\end{array}$ \\
\hline $\ln$ (House Price Index) & -2.2372 & -0.9099 & -2.5931 & 0.3303 & $\begin{array}{l}-5.0826^{*} \\
\text { [March 2008] }\end{array}$ & $\begin{array}{l}-5.7720 \\
{[2007: 11} \\
2009: 01]\end{array}$ & $\begin{array}{l}-4.8715^{* *} \\
{[2006: 10} \\
2008: 10]\end{array}$ \\
\hline Yield Spread & -0.8702 & -0.8867 & -0.6464 & $0.7456^{* *}$ & $\begin{array}{l}-5.6978^{* *} \\
\text { [October 2008] }\end{array}$ & $\begin{array}{l}-5.0559 \\
{[2008: 04} \\
2009: 04]\end{array}$ & $\begin{array}{l}-5.6644^{* *} \\
{[2008: 01} \\
2009: 01]\end{array}$ \\
\hline TED & -2.1354 & -2.0111 & -2.1413 & 0.3437 & $\begin{array}{l}-3.7427 \\
{[\text { February }} \\
2008]\end{array}$ & $\begin{array}{l}-4.1139 \\
{[2007: 03} \\
2008: 11]\end{array}$ & $\begin{array}{l}-5.9759^{* *} \\
{[2007: 06} \\
2009: 03]\end{array}$ \\
\hline $\ln ($ FTSE 100) & -1.9347 & -1.2743 & -1.7848 & 0.1908 & $\begin{array}{l}-3.2745 \\
\text { [September } \\
\text { 2009] }\end{array}$ & $\begin{array}{l}-5.1457 \\
{[2007: 11} \\
2009: 03]\end{array}$ & $\begin{array}{l}-5.2724^{* *} \\
{[2007: 10} \\
2008: 09]\end{array}$ \\
\hline
\end{tabular}

Notes: ADF is a test of the unit root null hypothesis where the test regression contains a constant and no deterministic components. DFGLS and KPSS tests are known as Dickey-Fuller test with GLS detrending, and the Kwiatkowski, Phillips, Schmidt, and Shin test respectively. The DFGLS test involves estimating the standard ADF test equation with the GLS de-trended data as opposed to the original series. The DFGLS contains a constant and no deterministic components. The KPSS test differs from other unit root tests in the sense that the time series is assumed to be trend-stationary under the null. The KPSS contains a constant and no deterministic components. Zivot-Andrews (ZA) test allows for structural break in both intercept and trend.

"Indicate t-values being significant at $1 \%$ level, ${ }^{* *}$ indicate t-values being significant at $5 \%$ level implying no unit root in the series. The asymptotic 1 per cent critical values for the ADF test is: -3.51 . The critical value at 1 percent level for the Elliott-Rothenberg-Stock DF-GLS: -2.60 . The asymptotic 1 per cent critical values for the Phillips Perron test is: -3.51 . The asymptotic 1 per cent critical values for the KPSS test is: 0.7390 . Under KPSS test, the null is stationary. The Critical Values at 1\% level for the Zivot and Andrews test are: -5.57 and at $5 \%$ level: -5.08 , the numbers in brackets are the estimated structural breaks based on the ZA test. Lumsdaine-Papell Unit Root Test critical values are -7.1900 ( $1 \%$ sig level), -6.6200 (5\% sig level) and -6.3700 (10\% sig level). Critical values of the endogenous two-break LM unit-root test at $10 \%, 5 \%$ and $1 \%$ level of significance are $-3.504,-3.842$ and -4.545 respectively from Table 2 in Lee and Strazicich (2003: 1084). 
Table 4

VAR Lag Order Selection.

\begin{tabular}{llll}
\hline Lag & LR & FPE & AIC \\
\hline 0 & NA & $4.21 \mathrm{e}-05$ & $4.21 \mathrm{e}-05$ \\
1 & 819.1956 & $6.26 \mathrm{e}-10$ & $6.26 \mathrm{e}-10$ \\
2 & 48.5302 & $4.64 \mathrm{e}-10$ & $4.64 \mathrm{e}-10$ \\
3 & $39.4839^{*}$ & $3.81 \mathrm{e}-10^{*}$ & $3.81 \mathrm{e}-10^{*}$ \\
4 & 19.6311 & $4.23 \mathrm{e}-10$ & $4.23 \mathrm{e}-10$ \\
5 & 19.3100 & $4.67 \mathrm{e}-10$ & -9.5963 \\
6 & 14.9761 & $5.54 \mathrm{e}-10$ & -9.7035 \\
7 & 15.8325 & $6.40 \mathrm{e}-10$ & -10 \\
8 & 16.8472 & $7.17 \mathrm{e}-10$ & $-9.7130^{*}$ \\
9 & 19.2021 & $7.48 \mathrm{e}-10$ & -10 \\
10 & 19.4224 & $7.61 \mathrm{e}-10$ & $-8.40 \mathrm{e}-10$ \\
\end{tabular}

Notes: * Indicates lag order selected by the criterion. LR: sequential modified LR test statistic (each test at 5\% level), FPE: Final prediction error, AIC: Akaike information criterion, HQ: Hannan-Quinn information criterion. The optimal lag length is found to be 3 months across different lag selection criteria.

tests were subject to criticism for the way they treated the existence of breaks under the null hypothesis. As breaks were absent under the null hypothesis of unit root in the traditional tests, there may be a tendency for these tests to suggest evidence of stationarity with breaks, see Lee and Strazicich (2003). Therefore, Lee and Strazicich (2003) proposed a two break minimum Lagrange Multiplier (LM) unit root test, where the alternative hypothesis explicitly implied that the series was trend stationary. In addition, Ben-David et al. (2003) showed that not allowing for multiple breaks may lead to the non-rejection of the null of unit root by those tests that only allow for one break.

Along with the standard unit root tests (ADF and the Elliott-Rothenberg-Stock-DF-GLS, Phillips-Perron, Kwiatowski Phillips Shmidt Shin (KPSS) tests), we also conduct more recent stationarity tests that allow for the presence of one or more structural breaks (Zivot-Andrews, Lumsdaine-Papell, and Lee-Strazicich tests). In total, seven unit-root tests have been conducted on the CDS premium, house price index, yield curve, TED spread and the FTSE100 index. The results from these tests are summarized in Table 3.

Response to Generalized One S.D. Innovations \pm 2 S.E.

Response of TED to TED

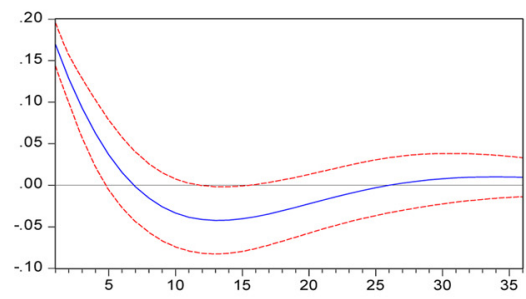

Response of LFTSE to TED

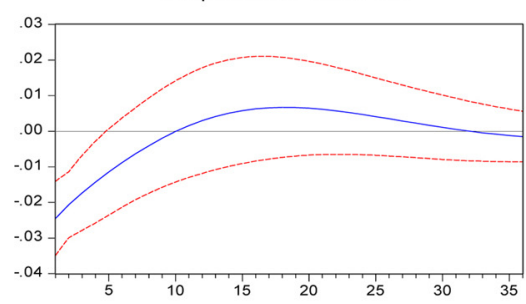

Response of LOGCDS to TED

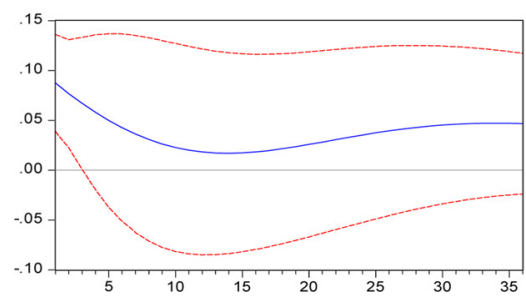

Response of YIELDCURVE30 to TED

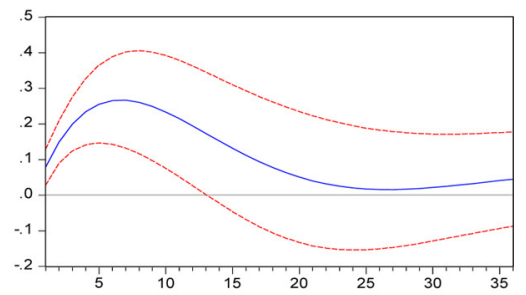

Response of LOGHOUSEPRICE to TED

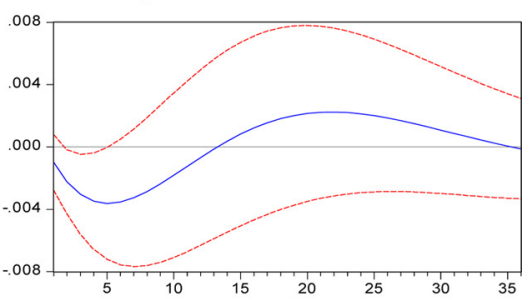

Fig. 2. Impulse responses to a shock in TED spread.

Notes: This figure indicates the outcome of the impulse responses to a shock in TED spread. The VAR model is formulated as follows: TED spread, yield spread, LOG (FTSE 100), LOG (House Price Index), and LOG (CDS premium). 
Response to Generalized One S.D. Innovations \pm 2 S.E.

Response of TED to YIELDCURVE30

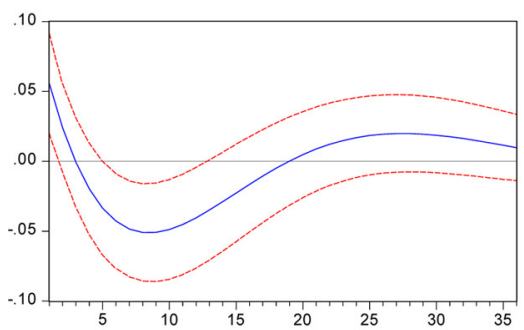

Response of LFTSE to YIELDCURVE30

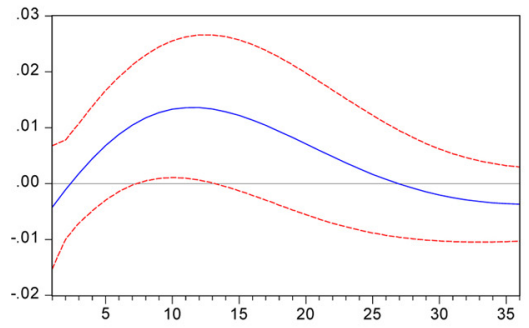

Response of LOGCDS to YIELDCURVE30

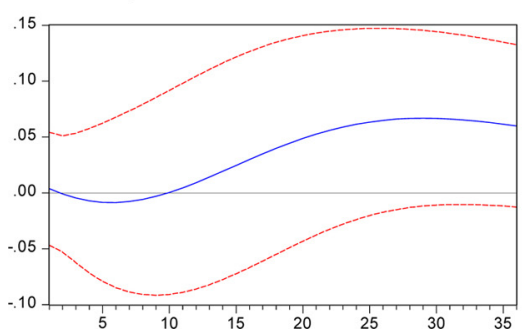

Response of YIELDCURVE30 to YIELDCURVE30

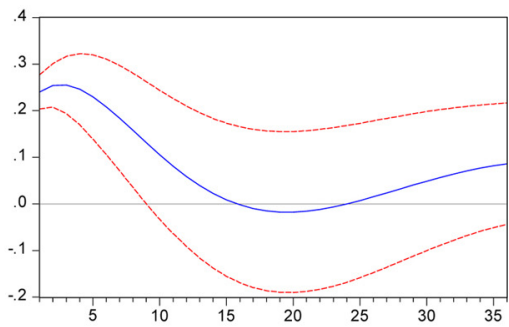

Response of LOGHOUSEPRICE to YIELDCURVE30

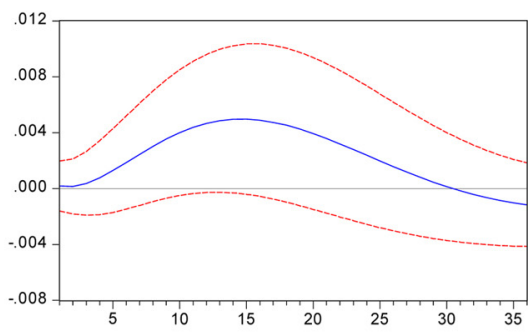

Fig. 3. Impulse responses to a shock in Yield Spread.

The second column of Table 3 illustrates the outcome of the unit root test for $[\ln (C D S), \ln ($ House Price Index), yield spread, TED and $\ln$ (FTSE 100)] using the ADF test. The results indicate that at $1 \%$ level, all the variables [ $\ln (\mathrm{CDS}), \ln$ (House Price Index), yield spread, TED and $\ln$ (FTSE 100)] contain a unit root and according to this specific ADF test they are non-stationary. The third column of Table 3 shows the outcome of the Elliott-Rothenberg-Stock DF-GLS test - which is considered to be a more powerful test relative to the ADF test. The results confirm the existence of a unit root (or non-stationarity) in the variables. The fourth and fifth columns of Table 3 illustrate the results obtained from the Phillips Perron test, which, similar to the previously conducted ADF and the DF GLS tests, indicate that all variables $[\ln (\mathrm{CDS}), \ln ($ House Price Index), yield spread, TED and $\ln$ (FTSE 100)] are non-stationary. In the fifth column of Table 3, the Kwiatowski Phillips Shmidt Shin (KPSS) tests indicate that $\ln (\mathrm{CDS})$ premium and the yield spread are non-stationary, implying that these two variables contain a unit root, while the TED spread, $\ln$ (FTSE100) and the $\ln$ (House Price Index) turn out to be all stationary. The mixed evidence in the stationarity resulting from the traditional unit root tests lead us to conduct stronger and more reliable stationarity tests that allow for the occurrence of structural breaks. Therefore, we employ the Zivot and Andrews test, the Lumsdaine and Papell, and the Lee-Strazicich test that allow for the occurrence of one or two structural breaks.

It should be noted that the Zivot and Andrews (1992) test reflects only one structural break in each variable. However, there is always a possibility that the series were subject to multiple structural breaks. This follows the recent events that occurred in the global financial system. In fact, the severe financial crisis strongly affected not only the credit risk in the banking sector but also the housing market, by causing structural breaks in the data. At first, there was the housing bubble which later translated into the global financial crisis. This means that considering only one endogenous break can turn out to be insufficient and may lead to a loss of information especially when there is more than one break. The results of the Zivot and Andrews, the Lumsdaine and Papell and the Lee-Strazicich tests are summarized in the last three columns of Table 3.

The outcome from the Zivot and Andrews test is summarized in column 6 of Table 3. As such, once we allow for a break in the variables, $\ln (\mathrm{CDS}), \ln$ (House price Index), and the yield spread turn out to be stationary. The tests for $\ln (\mathrm{CDS})$ and the yield spread are significant at $1 \%$ level. It is therefore possible to reject the null hypothesis of the presence of a unit root. The structural break in $\ln (\mathrm{CDS})$ occurred in August 2008, while the break point for the yield spread was in October 2008. This coincides with the collapse of Lehman Brothers and the deterioration of the conditions of the banking sector. Similarly, the 
Response to Generalized One S.D. Innovations \pm 2 S.E.

Response of TED to LFTSE

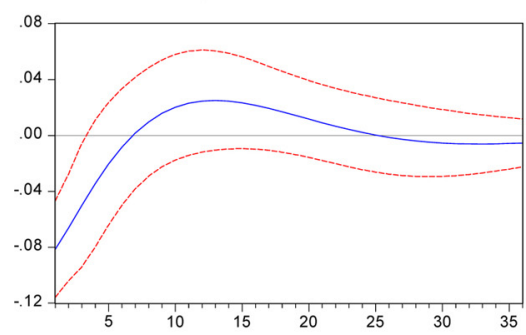

Response of LFTSE to LFTSE

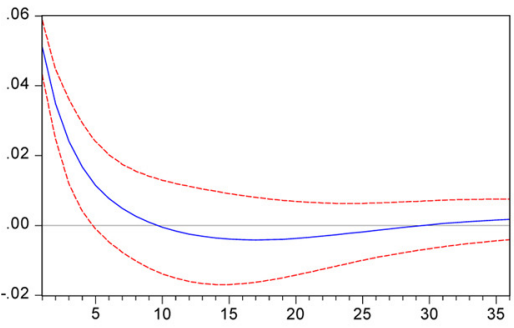

Response of LOGCDS to LFTSE

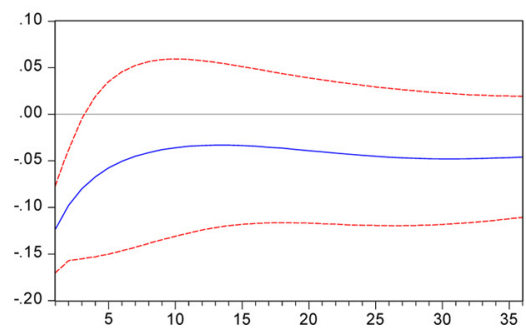

Response of YIELDCURVE30 to LFTSE

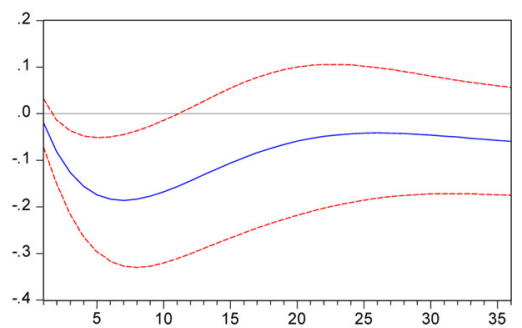

Response of LOGHOUSEPRICE to LFTSE

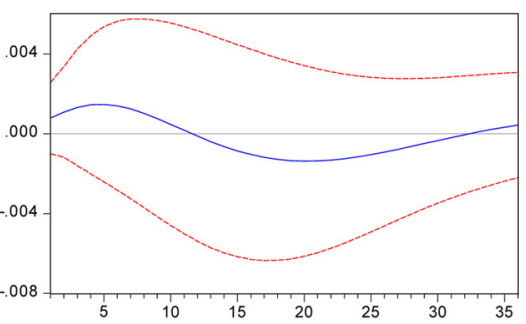

Fig. 4. Impulse responses to a shock in FTSE-100.

$\ln$ (House Price Index) is significant at the $5 \%$ level; so it is possible to reject the null hypotheses and consider $\ln$ (House Price Index) as stationary. The structural break point in the housing market was in March 2008. This corresponds to the period when the CDS premium peaked at 220 basis points, as compared to its pre-crisis value of July 2007 when it averaged 9 basis points. It should be noted that this contradicts the results from ADF, DF GLS, Phillips Perron and KPSS tests which show that all of the variables in the model were non-stationary. The two variables that still contain a unit root, even after allowing for a structural break in ZA test, are $\ln ($ FTSE 100) and TED. We therefore consider Lumsdaine and Papell (1997) who extended the Zivot and Andrews (1992) model to accommodate two endogenous breaks under the alternative hypothesis of stationarity. However, these endogenous tests did not consider breaks under the null hypothesis of a unit root (as the null is not rejected in column 7) and hence there may be a tendency for these tests to suggest evidence of stationarity with breaks, see Lee and Strazicich, (2003). We therefore consider the Lagrange Multiplier (LM) unit root test developed by Lee-Strazicich, with two endogenous breaks under the null and the alternative hypothesis of stationarity. The results of Lee-Strazicich test with two endogenously determined structural breaks indicate the rejection of the null of unit root of all variables, see column 8 , Table 3.

The estimated break locations can make a difference to the test results in small samples. It is for this reason the LM tests can be slightly more powerful than the DF version tests. Regardless of the order of integration, Sims et al. (1990) showed that the OLS estimates of a VAR model in levels are still consistent. Given the mixed results with regard to the stationary properties of the variables, we estimated different recursive VAR models in levels.

\section{VAR method and results}

In this paper, we build upon the work of Benbouzid and Mallick (2013), which focuses on establishing the long-run relationship between the CDS premium and its determinants, by focusing on investigating the short-run dynamics of the factors driving the CDS premium. As such, we employ a VAR model to analyse the short-run effects of shocks in house prices and money, credit and stock market variables on CDS premium. We first need to establish the optimal number of lags to 
Response to Generalized One S.D. Innovations \pm 2 S.E.

Response of TED to LOGHOUSEPRICE

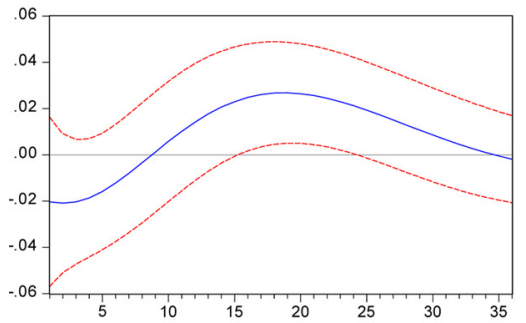

Response of LFTSE to LOGHOUSEPRICE

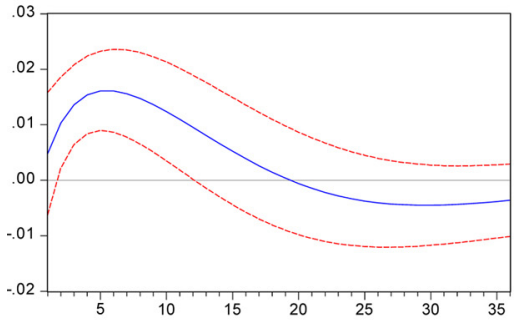

Response of LOGCDS to LOGHOUSEPRICE

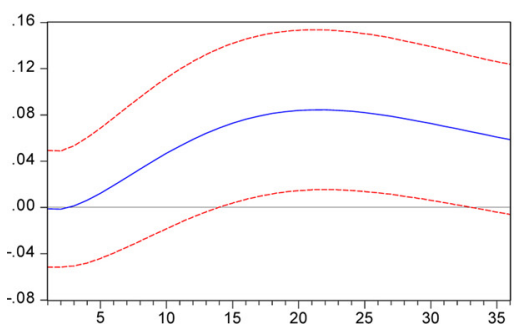

Response of YIELDCURVE30 to LOGHOUSEPRICE

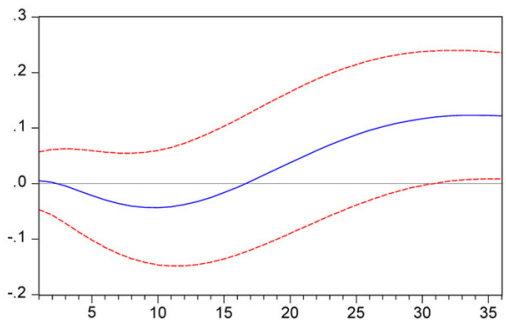

Response of LOGHOUSEPRICE to LOGHOUSEPRICE

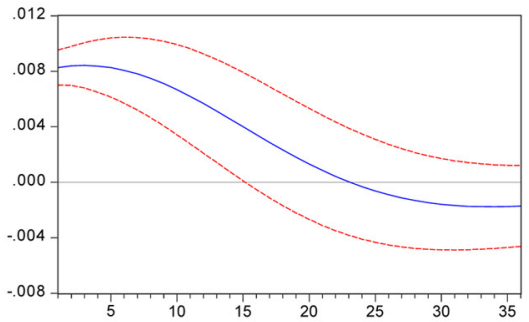

Fig. 5. Impulse responses to a shock in House Price.

be used in our model. For this purpose, we use the VAR Lag Order Selection Criteria, the results of which are presented in Table 4.

From Table 4, it is clear that the Sequential Modified LR test Statistic, Final prediction error, Akaike information criterion as well as the Hannan-Quinn information criterion all indicate that the optimal lag length for a VAR model is 3 lags which is therefore used in our study. We now proceed to analyse the significance of these CDS premium determinants in the shortrun. For this purpose, a VAR model is implemented to explore the degree of interdependence between the CDS premium and the house price index, yield spread, TED spread and the FTSE 100 index.

The short-run analysis is achieved by deriving impulse response functions via a VAR model. The main purpose of the VAR estimation is to obtain orthogonalisation of the error terms for the impulse response analysis. The restricted VAR defines the relationship between the VAR residuals, that is, the unexpected shocks, and the structural shocks, which are exogenous and uncorrelated with each other. This can be defined as follows:

$A e_{t}=B u_{t}$, with: $E\left[u_{t} u_{t}^{\prime}\right]=I$ Where: $u_{t}$ is the vector of uncorrelated structural shocks ( $I$ is the identity matrix), while $A$ and $B$ are the matrices that define the linear relationship between the structural shocks and the reduced-form VAR residuals $e_{t}$. The following recursive structure is imposed to identify the different shocks. The recursive VAR system tries to identify the structure of the model by constructing the error term in each regression to be uncorrelated with the error in the preceding equations. This is done by including the contemporaneous values of the variables as regressors in the form of a recursive ordering of variables, which is known as Cholesky decomposition of the variance-covariance matrix of the reduced form residuals.

$$
\left[\begin{array}{c}
e_{t d} \\
e_{y d} \\
e_{f t} \\
e_{h p} \\
e_{c d}
\end{array}\right]=\left[\begin{array}{ccccc}
a_{11} & 0 & 0 & 0 & 0 \\
a_{21} & a_{22} & 0 & 0 & 0 \\
a_{31} & a_{32} & a_{33} & 0 & 0 \\
a_{41} & a_{42} & a_{43} & a_{44} & 0 \\
a_{51} & a_{52} & a_{53} & a_{54} & a_{55}
\end{array}\right]\left[\begin{array}{c}
u_{t d} \\
u_{y d} \\
u_{f t} \\
u_{h p} \\
u_{c d}
\end{array}\right]
$$


Response to Generalized One S.D. Innovations \pm 2 S.E.

Response of TED to LOGCDS

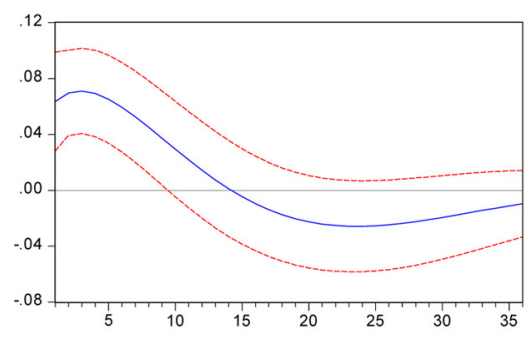

Response of LFTSE to LOGCDS

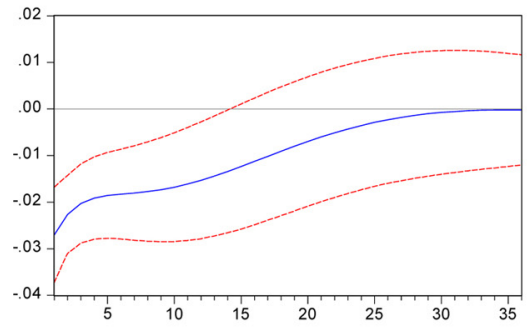

Response of LOGCDS to LOGCDS

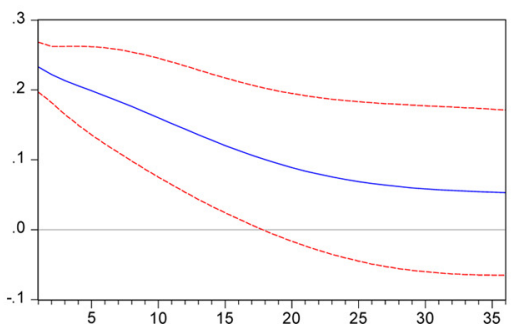

Response of YIELDCURVE30 to LOGCDS

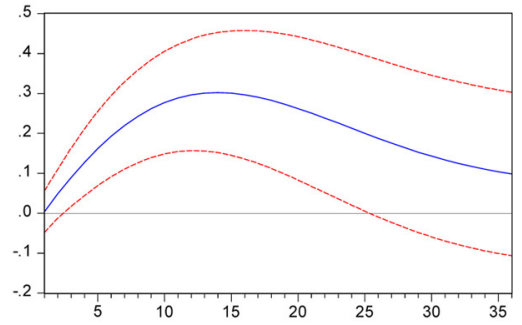

Response of LOGHOUSEPRICE to LOGCDS

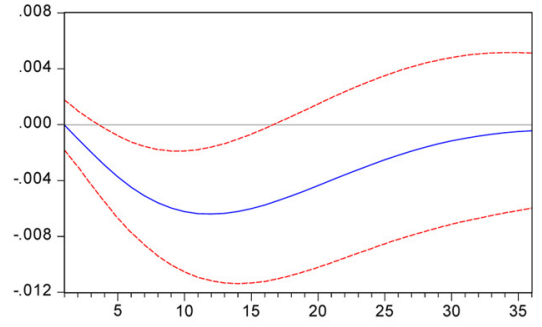

Fig. 6. Impulse responses to a shock in CDS premium.

where $e_{t d}$ is the reduced-form residual from the TED equation, $e_{y d}$ is the residual from the yield spread equation, $e_{f t}$ comes from the FTSE equation, $\mathrm{e}_{h p}$ is from the house price equation, and $\mathrm{e}_{c d}$ is derived from the CDS premium equation. This is the assumed ordering of the variables in this model with a recursive sequencing of the contemporaneous restrictions. This recursive structure means that the first variable in the ordering is not affected by shocks to the other variables, but shocks to the first variable affect the other ones; the second variable affects the third and fourth ones, but it is not affected contemporaneously by them, and so on.

The VAR is formulated with the following ordering of the endogenous variables: TED spread, yield spread, $\ln$ (FTSE 100), $\ln$ (House Price Index), and $\ln$ (CDS premium). The reason behind this specific ordering stems from the theoretical ordering of the variables that should run from the more exogenous to the less exogenous variables. In fact, both the liquidity spread and the yield spread are more likely to be determined by the monetary policy and the state of the economy prevailing during the specific period. However, the FTSE 100 index and house price index are less exogenous than the TED spread and the yield spread and are consequently placed later in the ordering. The CDS premium is assumed to be affected by all of the previously included variables and is therefore placed last in the ordering.

This VAR model with the above recursive identification strategy enables us to perform an analysis of unexpected shocks and interpret the shocks in economic terms. We only impose short-run contemporaneous restrictions as mentioned in the earlier matrix to deal with the problem of identification by choosing a lower triangular matrix with positive diagonal elements that helps derive the Cholesky factorisation. This is done in order to achieve orthogonalization of the reduced form innovations, as our objective is to identify the five shocks discussed earlier.

Figs. 2-6 show the responses from the recursive VAR model. In each figure, the dynamic effect of each shock is reported with two standard error band around the point estimate. Fig. 2 shows that a one standard deviation shock to TED spread increases the bank CDS premium on impact. A positive shock to liquidity premium increases the yield spread, lowers stock prices and house prices in terms of immediate impact effect and results in an increase in the CDS premium. The effects are significant in the short-run and it dies out in the medium term.

In Fig. 3, a shock to the yield spread has a significant positive impact on liquidity premium and stock prices, with no significant impact on house prices and the CDS premium. A positive shock to the yield spread has an immediate positive 


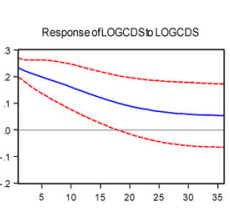

Response of TED toLOGCDS

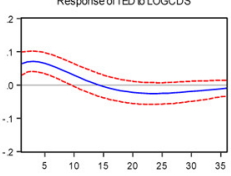

Response oIYELDCURVESO bLOGCDS

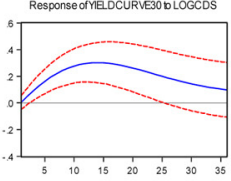

Response ofLFSEE LOGCDS

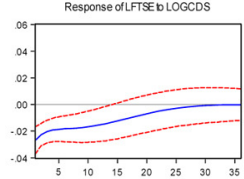

REsponse ofLOGHOUSERRICE D LOGCDS

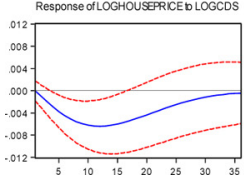

Response ofLOOGCOSD TID

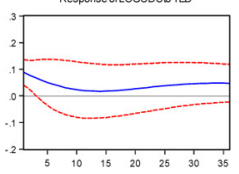

Response ofTED $t$ TED

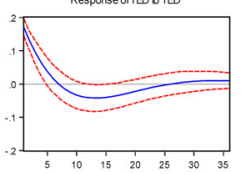

Response of YYEDCURVESO $\mathrm{D}$ TE

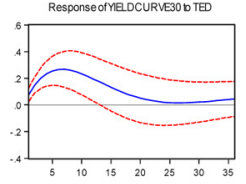

Response ofLFSSED TED

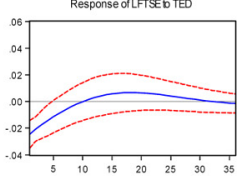

Response of LOGHOUSERRICED TED

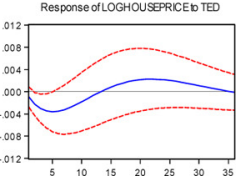

Response to Generalized One S.D. Innovations \pm 2 S.E.

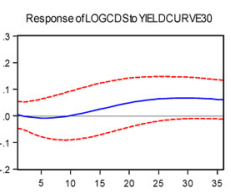

Response ofTED o YEDCURVEZO
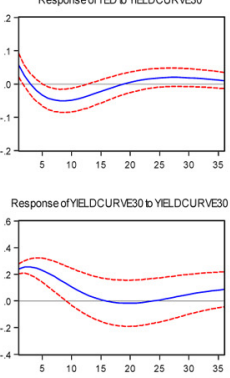

Response ofLLTSE Y YEDCURVEZO

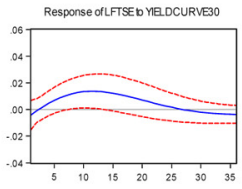

Response OALOGHOUSERRCED YEEDCURVES

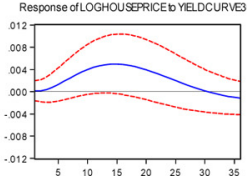

Response of LOGCDSDLITSE

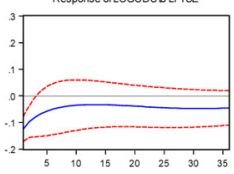

Response of TID $\mathrm{DLFTSE}$

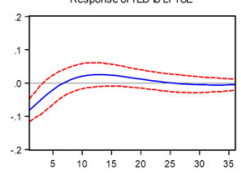

Response omEDCURVEZO bLFTS

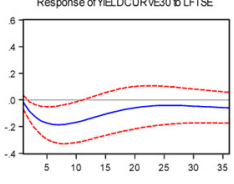

Response of LFTSEEto LFTS

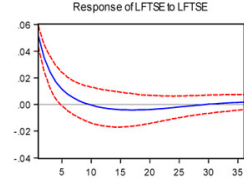

Response ofLOGHOUSERRICED LFTSE

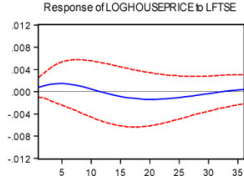

Responseo of LOGCDSDLOGHOUSFRRICE

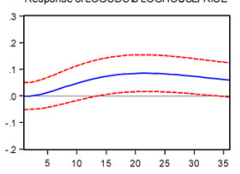

Response of TED DL LOGHOUSEPRICE

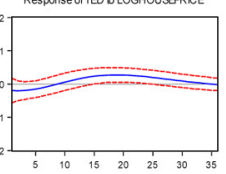

Response OMEDCURVESO DLOGHOUSERRC

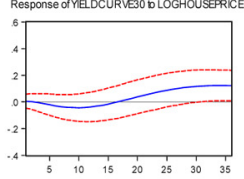

RPDOnSe ofLFSE L LOGHOUSERRIC
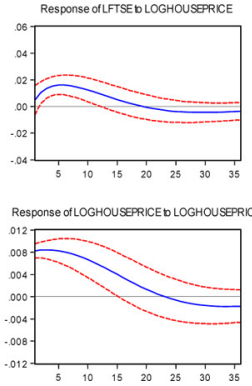

Fig. 7. Generalised impulse responses with change in ordering for robustness.

Notes: The ordering is reversed here as follows: $\log (\mathrm{cds})$ ted yieldcurve $30 \log (\mathrm{ftse}) \log$ (houseprice). The graphs that are plotted vertically demonstrate the response of the variables to each shock in the same sequence as the above ordering.

effect on liquidity premium, which lowers the FTSE 100 index on impact but the effect thereafter becomes positive as the shock dies out. As the standard error band includes zero and becomes wider as the time horizon increases, the effect on house prices and the CDS premium is not significant even in the long run.

Fig. 4 shows that a positive price shock to FTSE 100 index lowers the banking sector CDS premium, long-term yield and TED spreads. An increase in the FTSE 100 index has a favourable immediate impact effect in lowering the level of CDS premium in the short run, although the disturbance has an insignificant effect in the medium term. The negative relationship between the CDS premium and the FTSE 100 index suggests that as FTSE fell during the crisis, much of its market capitalization was made up of bank stocks indicating stress within the banking sector thereby raising the banking sector CDS premium.

Fig. 5 shows that a one standard deviation shock in house price index increases the bank CDS premium in the medium term, making the house price channel as a key factor in explaining CDS premiums. Also, a house price shock increases the TED spread, the yield spread and FTSE index in the medium term. It is clear from Fig. 5 that the response of CDS premium to a shock in the house price index is positive and significant in the medium term. We observe a higher level of credit risk in the medium-term following a house price shock, as people have easy access to the mortgage market through low interest rates and a low cost of borrowing, raising house prices and higher credit risk in the long-run as shown in Fig. 5.

Fig. 6 shows that if a shock originates in the loan market as reflected in a shock to the CDS premium, such a shock gives rise to driving down house prices given that the level of borrowing falls due to higher credit risk. In other words, following a positive shock to credit risk, house price tends to decline. The responses of the liquidity premium and yield spread to a CDS premium shock mirror the response of FTSE 100 and house price indices to the same disturbance. Fig. 6 shows that UK TED spread initially increases following a shock to the CDS premium and in the medium-term, UK TED spread narrows. The liquidity factors tend to get embedded in the CDS premium, showing a direct relationship between the two at the aggregatelevel, whereas the story can be different at the individual bank-level. In addition, a positive shock to the CDS premium lowers house prices, because when the overall risk perception in the CDS market increases, financial institutions and banks tend to lend less to borrowers, thereby reducing demand for housing. Consequently, house prices decline, the equity index falls, the long-term bond yield increases and TED spread increases.

The traditional approach has been to use Cholesky decomposition to generate impulse responses, but the method is sensitive to the ordering of variables, so we explore generalized impulse response functions (GIRF) to analyse the impact of shocks to specific equations on each of the variables in the system, see Koop et al. (1996). GIRF is invariant to ordering 
Table 5

Variance decomposition of model variables.

\begin{tabular}{|c|c|c|c|c|c|c|}
\hline Period & S.E. & TED & YIELDCURVE & Log FTSE & Log HOUSEPRICE & Log CDS \\
\hline & \multicolumn{6}{|c|}{ Variance Decomposition of TED: } \\
\hline 1 & 0.17 & 100.00 & 0.00 & 0.00 & 0.00 & 0.00 \\
\hline 6 & 0.28 & 75.20 & 10.39 & 0.04 & 0.33 & 14.03 \\
\hline 12 & 0.33 & 58.47 & 16.95 & 0.34 & 0.44 & 23.81 \\
\hline 24 & 0.37 & 56.43 & 15.92 & 0.41 & 4.22 & 23.02 \\
\hline \multirow[t]{2}{*}{36} & 0.38 & 51.97 & 16.64 & 0.45 & 4.69 & 26.25 \\
\hline & \multicolumn{6}{|c|}{ Variance Decomposition of YIELDCURVE30: } \\
\hline 1 & 0.24 & 10.80 & 89.20 & 0.00 & 0.00 & 0.00 \\
\hline 6 & 0.71 & 51.27 & 41.86 & 3.79 & 0.04 & 3.04 \\
\hline 12 & 1.05 & 53.80 & 20.82 & 4.19 & 0.10 & 21.09 \\
\hline 24 & 1.45 & 33.53 & 11.59 & 3.18 & 1.28 & 50.42 \\
\hline \multirow[t]{2}{*}{36} & 1.61 & 27.76 & 10.65 & 3.54 & 7.39 & 50.66 \\
\hline & \multicolumn{6}{|c|}{ Variance Decomposition of Log FTSE: } \\
\hline 1 & 0.05 & 23.14 & 0.63 & 76.24 & 0.00 & 0.00 \\
\hline 6 & 0.08 & 25.58 & 7.16 & 47.03 & 10.48 & 9.75 \\
\hline 12 & 0.11 & 16.27 & 14.55 & 28.88 & 14.22 & 26.08 \\
\hline 24 & 0.12 & 15.05 & 16.07 & 22.04 & 11.98 & 34.87 \\
\hline \multirow[t]{2}{*}{36} & 0.12 & 15.00 & 16.16 & 21.55 & 12.93 & 34.36 \\
\hline & \multicolumn{6}{|c|}{ Variance Decomposition of Log HOUSEPRICE: } \\
\hline 1 & 0.01 & 1.44 & 0.40 & 0.13 & 98.02 & 0.00 \\
\hline 6 & 0.02 & 10.72 & 4.95 & 0.23 & 76.41 & 7.70 \\
\hline 12 & 0.03 & 7.13 & 13.17 & 0.50 & 53.76 & 25.44 \\
\hline 24 & 0.04 & 5.94 & 17.01 & 0.66 & 35.62 & 40.77 \\
\hline \multirow[t]{2}{*}{36} & 0.05 & 6.45 & 16.59 & 0.69 & 35.02 & 41.26 \\
\hline & \multicolumn{6}{|c|}{ Variance Decomposition of Log CDS: } \\
\hline 1 & 0.23 & 14.08 & 1.31 & 15.26 & 0.38 & 68.97 \\
\hline 6 & 0.53 & 9.20 & 1.55 & 7.02 & 0.71 & 81.51 \\
\hline 12 & 0.69 & 6.31 & 1.12 & 5.17 & 3.49 & 83.91 \\
\hline 24 & 0.84 & 5.30 & 3.11 & 5.36 & 13.76 & 72.47 \\
\hline 36 & 0.93 & 7.09 & 6.46 & 6.02 & 19.19 & 61.25 \\
\hline
\end{tabular}

Notes: The Cholesky Ordering: TED YIELDCURVE Log FTSE Log HOUSEPRICE Log CDS; The variables in each column denotes shocks or innovations in that variable.

and is based on the historical covariance structure of idiosyncratic shocks. Thus GIRF results are more robust than the orthogonalized method, see Pesaran and Shin (1998).

We therefore checked for robustness by changing the ordering of variables with CDS being the first in the ordering as opposed to being the last in the variable ordering, within the GIRF method. However, the results remained robust as shown in Fig. 7.

As seen in Fig. 7, the generalized impulse responses tend to be insensitive to the variable ordering. So our results clearly show that positive house price shocks that drive credit risk as reflected in the CDS premium in the medium-run remained robust in responding positively even if we alter the ordering of variables, and shocks to credit risk contribute to lowering house prices as it happened in the aftermath of the recent credit crisis, see Fig. 7, last column, first row.

We explore this issue further by means of variance decomposition analysis as shown in Table 5 , that shows that the house price shock explains nearly $20 \%$ of the long-run forecast-error variance of the CDS premium. By contrast, the other shocks each explain under $8 \%$ of this forecast-error variance. Table 5 also reveals that the own innovations of CDS premium explain about $61 \%$ of the variation in the CDS premium.

\section{Conclusion}

CDS premiums are amongst the most transparent and reliable indicators of credit risk. With the onset of the financial crisis, serious concerns were raised with regard to the underlying trading incentives and the impact of such instruments on financial stability. The financial crisis resulted in large house price falls. As a result many borrowers fell into negative equity or those who had insufficient income started to default, increasing the CDS premium. This paper contributes to the empirical literature on CDS premium as it is one of the first to conduct a multivariate analysis of the factors affecting the CDS premium. The VAR model is used to conduct a short-run analysis by imposing short-run restrictions to identify the five shocks arising from the CDS premium, namely: the CDS premium, the house price index, the yield spread, the TED spread, and the FTSE100. The VAR analysis allows us to capture the empirical interrelationships among these variables.

Our findings indicate that a positive shock to house prices significantly increases the CDS premium in the UK banking sector over the medium-term. Our results are robust to changing the ordering of the variables in the VAR. We also show that the strongest variable that is able to explain the CDS premium is the house price index, which in turn is influenced by yield spread and TED spread. 
In addition, we find that a positive shock to the CDS premium reduces house prices. This is because an increase in the CDS premium causes financial institutions and banks to lend less, reducing the demand for housing and consequently placing downward pressure on house prices. None of the other variables in the model have a direct impact on CDS premium but they indirectly influence the CDS premium via their impact on house prices. By undertaking a variance decomposition analysis, we show that the house price shock explains over $19 \%$ of the long-run forecast-error variance of the CDS premium while shocks in the other variables each explain under $8 \%$ of this forecast-error variance.

Very limited literature existed on the drivers of CDS spreads before the financial crisis due to the opacity of this market and its lack of transparency. As the post-crisis literature did not effectively account for the role that house prices play in affecting banks' CDS spreads in a major crisis-hit economy, our research is the first, to our knowledge, to use a dynamic VAR setting to link the housing market to the CDS market in the light of the recent financial crisis. Although the crisis originated in the US, the UK financial institutions were heavily exposed to the US mortgage market making it necessary for us to assess the role of house prices in bank credit risk in the UK. A policy of low interest rates would typically lead to increased borrowing which will have to be matched by increased housing supply in order to keep house prices stable. If any element in the chain is not satisfied, this may give rise to major imbalances that may result in a housing bubble, which in turn can cause another crisis. Consequently, close supervision of the housing market is crucial in order to ensure systemic stability.

\section{References}

Aizenman, J., Hutchison, M., Jinjarak, Y., 2013. What is the risk of European sovereign debt defaults? Fiscal space, CDS spreads and market pricing of risk. J. Int. Money Finance 34, 37-59.

Alexander, C., Kaeck, A., 2008. Regime dependent determinants of credit default swap spreads. J. Bank. Finance 32 (6), 1008-1021.

Alper, C.E., Forni, L., Marc, G., 2012. Pricing of Sovereign Credit Risk: Evidence from Advanced Economies During the Financial Crisis. IMF Working Paper, IMF.

Altman, E.I., Brady, B., Resti, A., Sironi, A., 2005. The link between default and recovery rates: theory, empirical evidence and implications. J. Bus. 78, 2203-2227.

Anderson, R., Sundaresan, S., 2000. A comparative study of structural models of corporate bond yields: an exploratory investigation. J. Bank. Finance 24, 255-269.

Annaert, J., De Ceuster, M., Van Roy, P., Vespro, C., 2013. What determines Euro area bank CDS spreads? J. Int. Money Finance 32, $444-461$.

Apergis, N., Mamatzakis, E., 2014. What are the driving factors behind the rise of spreads and CDS of euro-area sovereign bonds? A FAVAR model for Greece and Ireland. Int. J. Econ. Bus. Res. 7 (1), 104-120.

Bedendo, M., Colla, P., 2015. Sovereign and corporate credit risk: evidence from the Eurozone. J. Corporate Finance 33, 34-52.

Ben-David, D., Lumsdaine, R., Papell, D.H., 2003. Unit root, postwar slowdowns and long-run growth: evidence from two structural breaks. Empir. Econ. $28(2), 303-319$.

Benbouzid, N., Mallick, S., 2013. Determinants of bank credit default swap spreads: the role of the housing sector. North Am. J. Econ. Finance 24, 243-259.

Blanco, R., Brennan, S., Ian, W., 2005. An empirical analysis of the dynamic relationship between investment-grade bonds and credit default swaps. J. Finance 60 (5), 2255-2281.

Bongaerts, D., de Jong, F., Driessen, J., 2011. Derivative pricing with liquidity risk: theory and evidence from credit default swap market. J. Finance 66, 203-240.

Boss, M., Scheicher, M., 2005. The Determinants of Credit Spread Changes in the Euro area. BIS papers 12, pp. 181-1999.

Byström, 2005. Credit Default Swaps and Equity Prices: The iTraxx CDS Index Market Working Paper. Department of Economics, Lund University.

Campbell, J.T., Taksler, G.B., 2003. Equity volatility and corporate bond yields. J. Finance 58, 2321-2349.

Cao, F., Yu, F., Zhong, Z., 2010. The information content of option-implied volatility for credit default swap valuation. J. Financial Mark. 13, 321-343.

Chiaramonte, L., Casu, B., 2013. The determinants of bank CDS spreads: Evidence from the financial crisis. Eur. J. Finance 19 (9), $861-887$.

Collin-Dufresne, P., Goldstein, R.S., Martin, J.S., 2001. The determinants of credit spread Changes. J. Finance 56, 2177-2207.

Cossin, D., Hricko, T., Aunon-Nerin, D., Huang, Z., 2002. Exploring for the Determinants of Credit Risk in Credit Default Swap Transaction Data: Is

Fixed-income Markets' Information Sufficient to Evaluate Credit Risk? FAME Research Paper Series Rp65. International Center for Financial Asset Management and Engineering.

Düllmann, K., Sosinska, A., 2007. Credit default swap prices as risk indicators of listed German banks. Financial Mark. Portfolio Manage. 21, 269-292.

Das, S.R., Hanouna, P., Sarin, A., 2009. Accounting-based versus market- based cross-sectional models of CDS spreads. J. Bank. Finance 33, 719-730.

Duffee, G.R., 1998. The relation between Treasury and corporate bond yield spreads. J. Finance 53, 2225-2241.

Duffie, D., Singleton, K.J., 1997. An econometric model of the term structure of interest-rate swap yields. J. Finance 52, 1287-1321.

Eom, Y.H., Helwege, J., Huang, J.Z., 2004. Structural models of corporate bond pricing: an empirical analysis. Rev. Financial Stud. 17, $499-544$.

Ericsson, J., Jacobs, K., Oviedo, R., 2009. The determinants of credit default swap premia. J. Financial Quant. Anal. 44, 109-132.

Estrella, A., Hardouvelis, G., 1991. The term structure as a predictor of real economic activity. J. Finance 45, 555-576.

Fabozzi, F.J., Cheng, X., Chen, R.R., 2007. Exploring the component of credit risk in credit default swaps. Finance Res. Lett. 4, 10-18.

Fehle, F., 2003. The components of interest rate swap spreads - theory and international evidence. J. Futures Mark. 23, 347-387.

Fontana, A., Scheicher, M., 2010. An Analysis of Euro Area Sovereign CDS and Their Relation with Government Bonds. ECB Working Paper no 1271.

Friedman, B.M., Kuttner, K.N., 1998. Indicator properties of the paper-bill spread: lessons from recent experience. Rev. Econ. Stat. 80, 34-44.

Galil, K., Soffer, G., 2011. Good news: bad news and rating announcements: an empirical investigation. J. Bank. Finance 35, $3101-3119$.

Galil, K., Shapir, O.M., Amiram, D., Ben-Zion, U., 2014. The determinants of CDS spreads. J. Bank. Finance 41, 271-282.

González-Hermosillo, B., 2008. Investors' Risk Appetite and Global Financial Market Conditions. Working Paper 08/85(IMF).

Houweling, P., Vorst, T., 2002. An Empirical Comparison of Default Swap Pricing Models. Working Paper, Erasmus University Rotterdam.

Hull, J.C., Predescu, M., White, A., 2004. The relationship between credit default swap spreads, bond yields, and credit rating announcements. J. Bank. Finance 28, 2789-2811.

In, F., Brown, R., Fang, V., 2003. Modelling volatility and changes in the swap spread. Int. Rev. Financial Anal. 12, 545-561.

Jarrow, R., Turnbull, S., 1995. Pricing derivatives on financial securities subject to credit risk. J. Finance 50, 53-86.

Karagozoglu, A., Jacobs, M., 2010. Measuring Credit Risk: CDS Spreads Vs. Credit Ratings. Working Paper, Office of the Comptroller of the Currency,

Division of Economic and International Affairs.

Kick, T., Koetter, M., 2007. Slippery slopes of stress: ordered failure events in german banking. J. Financial Stab. 3, 132-148.

Kobor, A., Shi, L., Zelenko, I., 2005. What Determines U.S. Swap Spreads? World Bank. Working Paper, No 62.

Koop, G., Pesaran, M.H., Potter, S.M., 1996. Impulse response analysis in nonlinear multivariate models. J. Econometr. 74, 119-147.

Lee, J., Strazicich, M.C., 2003. Minimum lagrange multiplier unit root test with two structural breaks. Rev. Econ. Stat. 85, 1082-1089.

Lekkos, I., Milas, C., 2001. Identifying the factors that affect interest-rate swap spreads: some evidence from the United States and the United Kingdom. J. Futures Mark. 21, 737-768. 
Litterman, R., Iben, T., 1991. Corporate bond valuation and the term structure of credit spreads. J. Portfolio Manage. 17, 52-64.

Longstaff, F.A., Schwartz, E.S., 1995. A simple approach to valuing risky and floating rate debt. J. Finance 50, 789-819.

Lumsdaine, R.L., Papell, D., 1997. Multiple trend breaks and the unit-root hypothesisl. Rev. Econ. Stat. 79 (2), $212-218$.

Mamatzakis, E., 2013. Are There Any Animal Spirits Behind the Scenes of the Euro Area Sovereign Debt Crisis? Greece -Hellenic Observatory Papers on Greece and Southeast Europe 72. Hellenic Observatory, LSE.

Norden, L., Weber, M., 2004. Informational efficiency of credit default swap and stock markets: the impact of credit rating announcements. J. Bank. Finance 28, 2813-2843.

Ötker-Robe, I; Podpiera, J., 2010. The Fundamental Determinants of Credit Default Risk for European Large Complex Financial Institutions. IMF Working Paper, WP/10/153.

Pan, J., Singleton, K.J., 2008. Default and recovery implicit in the term structure of sovereign CDS spreads. J. Finance 63, $2345-2384$.

Pesaran, H.H., Shin, Y., 1998. Generalized impulse response analysis in linear multivariate models. Econ. Lett. 58, 17-29.

Pesaran, M.H., Schuermann, T., Treutler, B.J., Weiner, S.M., 2006. Macroeconomic dynamics and credit risk: a global perspective. J. Money Credit Bank. 38 1211-1261.

Sims, C.A., Stock, J.H., Watson, M.W., 1990. Inference in linear time series models with some unit roots. Econometrica 58, $113-147$.

Skinner, F., Townend, T., 2002. An empirical analysis of credit default swaps. Int. Rev. Financial Anal. 11, $297-309$.

Tang, D.Y., Yan, H., 2010. Market conditions: default risk and credit spreads. J. Bank. Finance 34, 743-753.

Zhu, H., 2006. An empirical comparison of credit spreads between the bond market and the credit default swap market. J. Financial Serv. Res. $29,211-235$.

Zivot, E., Andrews, K., 1992. Further evidence on the Great Crash, The oil price shock, and the unit root hypothesis. J. Bus. Econ. Stat. 10 (3), $251-270$. 